\title{
Filtration and Retention Characteristics of Smoke Components in Filters *
}

\author{
by \\ Wen Jianhui $^{\text {}}$, Du Wen ${ }^{1}$, Peng Bin ${ }^{2}$, Zhang Xiaobing ${ }^{2}$, Xie Fuwei ${ }^{2}$, Liu Huimin ${ }^{2}$, and Zhong Kejun ${ }^{1}$ \\ ${ }^{1}$ Technology Center of China Tobacco Hunan Industrial Co. Ltd., Changsha 410007, China \\ ${ }^{2}$ Zhengzhou Tobacco Research Institute of CNTC, Zhengzou 450001, China
}

\section{SUMMARY}

The filtration and retention characteristics of nicotine, phenol, benzo $[a]$ pyrene $(\mathrm{B}[a] \mathrm{P}), 4-($ methylnitrosamino)-1(3-pyridyl)-1-butanone (NNK), crotonaldehyde, hydrogen cyanide $(\mathrm{HCN})$ and ammonia in conventional cellulose acetate fiber filters were investigated. By quantitatively analyzing their contents released in mainstream smoke and retained in filters, their filtration efficiencies, taken as the ratio of filter retention content to total yield, were determined under both International Organization for Standardization (ISO) and Health Canadian Intense (HCI) smoking regimes. Using a precision laser cutter, the filters were either cut transversely into 5-7 segments for longitudinal distribution pattern study, or cut transversely into 3 segments firstly and then each segment was cut concentrically into 3 concentric segments for spatial distribution pattern study. Contents of the named smoke components retained in these filter segments were quantitatively analyzed. The data were calibrated and then processed with interpolation analysis and polynomial fitting. The longitudinal distribution patterns for all components mentioned above, as well as spatial distribution patterns for nicotine, phenol, $\mathrm{HCN}$, ammonia and crotonaldehyde, were obtained. The filtration efficiencies of different smoke components varied between $24 \%$ and $15 \%$ for $\mathrm{HCN}, 87 \%$ and $92 \%$ for phenol under ISO and HCI smoking regimes respectively. The filtration efficiencies of all the studied components under HCI smoking were lower than under ISO smoking to different extents except phenol which showed the opposite trend. Different mainstream smoke components have their own retention behavior and distribution characteristics which are determined by the physical and chemical properties of the component and its interaction with cellulose acetate fiber and the glycerol triacetate within the filter. The diversity of retention distribution patterns of different components shows the high complexity of cigarette smoke filtration in filters. [Beitr. Tabakforsch Int. 26 (2014) 121-131]

\section{ZUSAMMENFASSUNG}

Es wurden die Filtrations- und Retentionseigenschaften von Nikotin, Phenol, Benzo $[a]$ pyren $(\mathrm{B}[a] \mathrm{P})$, 4-(Methylnitrosamino)-1-(3-pyridyl)-1-butanon (NNK), Crotonaldehyd, Cyanwasserstoff $(\mathrm{HCN})$ und Ammoniak in konventionellen Celluloseacetat-Faserfiltern untersucht. Mittels der quantitativen Analyse der im Hauptstromrauch freigesetzten und in Filtern aufgefangenen Mengen wurde ihre Filtrationseffizienz, bestimmt anhand des Verhältnisses der Filterrückhaltemenge zur Summe aus Filterrückhaltemenge und Ausbeute im Hauptstromrauch, nach den Rauchprotokollen der International Organization for Standardization (ISO) und Health Canada Intense (HCI) ermittelt. Mit einem Präzisionslaserschneider wurden die Filter entweder zur Untersuchung der longitudinalen Verteilungsmuster quer in 5-7 Segmente oder zur Untersuchung der räumlichen Verteilungsmuster zunächst quer in 3 Segmente und dann je Segment in 3 konzentrische Segmente geschnitten. Die Auffangmengen der genannten Rauchbestandteile in diesen Filtersegmenten wurden quantitativ ausgewertet. Die Daten wurden kalibriert und anschließend mittels Interpolationsanalyse und Polynomanpassung verarbeitet. Für alle oben genannten Bestandteile wurden die longitudinalen Verteilungsmuster ermittelt. Für Nikotin, Phenol, HCN, Ammoniak und Crotonaldehyd wurden zudem die räumlichen Verteilungsmuster ermittelt. Die Filtrationseffizienz unterschiedlicher Rauchbestandteile variierte jeweils nach 
den ISO- und HCI-Rauchprotokollen und lag zwischen $24 \%$ und $15 \%$ für HCN sowie zwischen $87 \%$ und $92 \%$ für Phenol. Die Filtrationseffizienz aller nach dem HCIProtokoll untersuchten Bestandteile war in unterschiedlichem Maße niedriger als nach dem ISO-Protokoll, mit Ausnahme von Phenol, das einen umgekehrten Trend zeigte. Verschiedene Hauptstromrauchbestandteile haben ihr eigenes Retentionsverhalten und ihre eigenen Verteilungseigenschaften, die sich aus den physikalischen und chemischen Eigenschaften des Bestandteils und seiner Interaktion mit den Celluloseacetatfasern und dem Triacetin im Filter ergeben. Die Vielfalt der Verteilungsmuster bei der Rückhaltung unterschiedlicher Bestandteile zeigt die hohe Komplexität der Filtration von Zigarettenrauch in Filtern. [Beitr. Tabakforsch Int. 26 (2014) 121-131]

\section{RESUME}

La présente analyse porte sur les caractéristiques de rétention et de filtration de la nicotine, du phénol, du benzo $[a]$ pyrène $(\mathrm{B}[a] \mathrm{P})$, de la nitrosamine NNK (4(méthylnitrosamino)-1-(3-pyridyl)-1-butanone), du crotonaldéhyde, de l'acide cyanhydrique (HCN) et de l'ammoniaque dans les filtres conventionnels en fibres d'acétate de cellulose. Par le truchement d'une analyse quantitative des contenus libérés dans la fumée principale et des contenus retenus dans les filtres, les performances de filtration, exprimées par le rapport entre le contenu de rétention du filtre et l'addition du contenu de rétention du filtre et du rendement de fumée principale, furent examinées selon les paramètres de fumage de l'Organisation internationale de Normalisation (ISO) et du Health Canadian Intense (HCI). A l'aide d'un découpeur au laser de précision, les filtres furent soit découpés transversalement en 5 à 7 segments en vue d'un examen du schéma de répartition longitudinale, soit découpés transversalement en trois segments qui furent ensuite chacun découpés de façon concentrique en trois sections en vue d'un examen du schéma de répartition spatiale. La composition des constituants de fumée susnommés retenus dans ces segments de filtres fut soumise à une analyse quantitative. Les données furent calibrées et ensuite traitées par interpolation et ajustement polynomial. Les schémas de répartition longitudinale pour l'ensemble des composants susmentionnés ainsi que les schémas de répartition spatiale pour la nicotine, le phénol, l'acide cyanhydrique, l'ammoniaque et le crotonaldéhyde purent être obtenus. Les performances de filtration des divers constituants de fumée varièrent respectivement de $24 \%$ à $15 \%$ pour l'acide cyanhydrique et de $87 \%$ à $92 \%$ pour le phénol selon les paramètres de fumage de l'ISO et du HCI. Les performances de filtration de tous les constituants relevées suivant les paramètres du HCI furent, à des degrés divers, inférieures aux performances relevées suivant les paramètres de l'ISO, à l'exception du phénol qui suivit une tendance opposée. Différents constituants de fumée principale présentent leur propre comportement de rétention et leurs propres caractéristiques de répartition, qui sont déterminés par les propriétés chimiques et physiques du constituant et son interaction avec la fibre d'acétate de cellulose et le triacétate de glycéryle contenus dans le filtre. La diversité des schémas de répartition et de rétention des différents constituants atteste de la grande complexité du processus de filtration de la fumée de cigarette dans les filtres. [Beitr. Tabakforsch Int. 26 (2014) 121-131]

\section{INTRODUCTION}

Cigarette filters can effectively reduce "tar", nicotine and other smoke component yields in mainstream smoke. Improvements in the filter filtration efficiency can play a key role in reducing mainstream smoke yields by machine smoking giving reduced exposure products and great attention has been paid to investigate the filtration efficiency and mechanisms of different filter materials to cigarette smoke particles (1-6). KEITH's study on smoke filtration mechanisms showed that there were three modes of smoke particle retention in filters: inertial impaction, diffusional deposition and direct interception (2). Filtration efficiencies of inertial impaction and diffusional deposition of smoke particles are related to smoke flow rate and particle diameters. Inertial impaction is favored by high flow rate and large particles, whereas diffusional deposition is favored by low flow rate and small particles. Direct interception is independent of smoke flow rate. KEITH and DENICK also advanced the inter-dependency between filtration efficiency and particle diameter (5). Particles of middle diameter are difficult to be retained, whereas larger or smaller particles are relatively easier to be retained. OVERTON studied relative contributions of these factors to cigarette smoke filtration (6). He showed that filter retention to smoke particles was mainly caused by diffusional deposition and direct interception, and the contribution of inertial impaction was less than $5 \%$. In addition, different filter materials, structure and ventilation also have strong relationships to filtration efficiency. MASAFUMI et al. compared the formaldehyde filtration efficiencies between cellulose acetate filter and active carbon filter with different carbon content (7). The research of HAN et al. showed the filtration differences between cellulose acetate fiber and modified polypropylene fiber (8). NORMAN et al. found that smoke yield decreases with filter ventilation increase, and the reduction levels among different components were not consistent (9). There has been much research on the effect of filter parameters and cigarette design on smoke composition and combustion mechanism (10-14). Much attention has also been paid to the influence of smoking regime on "tar", nicotine and other smoke components deliveries in particulate phase and gas phase (15-18). PURKIS' research showed that the temperature of the smoke passing through the filter under HCI smoking regime was significantly higher than under ISO smoking regime. The higher temperature causes less vapor phase adsorption onto the carbon filter and even some desorption in the later puffs rather than total saturation of the active carbon adsorption sites in the filter (16). However, there is still a lack of systematic investigation on filtration efficiency and particularly of retention characteristics and mechanisms of the reduction of different smoke components by filters.

In this paper, the filtration efficiencies of nicotine, phenol, $\mathrm{B}[a] \mathrm{P}, \mathrm{NNK}$, crotonaldehyde, $\mathrm{HCN}$ and ammonia in a cellulose acetate filter under ISO and HCI smoking regimes were analyzed. For a more comprehensive understanding, 
the filter retention concentration distribution patterns were investigated, in both longitudinal and concentric segments under both smoking regimes. The results should be helpful for future cigarette filter design and in understanding the retention mechanism of the studied mainstream smoke components in filters.

\section{EXPERIMENTAL}

\section{Cigarettes used}

Cigarette samples with conventional cellulose acetate filters were prepared for testing throughout the experiments. Their design specifications are shown in Table 1.

\section{Table 1. Design specification of cigarette sample.}

\begin{tabular}{lc}
\hline Cigarette description & Value \\
\hline Tobacco rod length $(\mathrm{mm})$ & 56 \\
Filter tip length $(\mathrm{mm})$ & 28 \\
Filter CA specification (denier) & $3.0 / \mathrm{Y} 32000$ \\
Filter overwrap length $(\mathrm{mm})$ & 35 \\
Filter ventilation $(\%)$ & 0 \\
Cigarette circumference $(\mathrm{mm})$ & 24.2 \\
Cigarette pressure drop $(\mathrm{Pa})$ & $1100 \pm 50$ \\
Blend style & Chinese flue-cured \\
Weight of cigarette $(\mathrm{g})$ & tobacco \\
Basis weight of cigarette paper $\left(\mathrm{g} / \mathrm{m}^{2}\right)$ & 0.91 \\
Cigarette paper permeability $(\mathrm{CU})^{\mathrm{a}}$ & 29 \\
Cigarette paper burn additive $(\%)^{\mathrm{b}}$ & 60 \\
\hline
\end{tabular}

a CORESTA unit (CU) is the air permeability unit $\left(\mathrm{cm}^{3} / \mathrm{min} / \mathrm{cm}^{2}\right)$, which can be obtained by measuring the flow of air $\left(\mathrm{cm}^{3} / \mathrm{min}\right)$ passing through $1 \mathrm{~cm}^{2}$ surface of the test piece at a measuring pressure of $1 \mathrm{kPa}$.

b Potassium citrate.

\section{Smoke collection and sample preparation}

The cigarettes were smoked on a Cerulean SM450 (Cerulean, Milton Keynes, UK) smoking machine according to both ISO (35 $\mathrm{mL}$ puff volume, 2 sec puff duration, 1 puff/min) and HCI (55 mL puff volume, 2 sec puff duration, $1 \mathrm{puff} / 30 \mathrm{sec})$ standard conditions. Total particulate matter (TPM) from 5 cigarettes under ISO smoking or 2 cigarettes under HCI smoking was collected on $44 \mathrm{~mm}$ Cambridge filter pads. In the filtration efficiency and retention distribution pattern study for nicotine, phenol, $\mathrm{HCN}$, ammonia and crotonaldehyde, 10 cigarettes were taken for one sample. As for $\mathrm{B}[a] \mathrm{P}$ and NNK, we took 20 cigarettes in the filtration efficiency study and 60 cigarettes in the retention distribution pattern study for one sample. Each sample was smoked and analyzed in 3 repetitions. The content of HCN and ammonia yield in mainstream smoke was determined in both particulate phase (Cambridge filter pad) and gas phase. Content of other components yield in mainstream smoke was determined only in particulate phase (crotonaldehyde was captured by Cambridge filter pads pre-soaked in derivative agent 2, 4-dinitrophenyl hydrazine).
The general principles of the methods summarized for the analysis of smoke components

Nicotine was extracted with isopropanol from Cambridge filter pads according to GB/T 23355-2009 procedure (19) and extracted from filters by isopropanol $(0.1 \%$ sodium hydrate) by YC/T 154-2001 procedure (20). Analysis was carried out on a GC (Agilent 6890, Agilent Technologies, Santa Clara, CA, USA) with a DB-35MS glass capillary column and flame ionization detector (FID), with detector temperature set at: $280{ }^{\circ} \mathrm{C}$, sample inlet temperature: $250{ }^{\circ} \mathrm{C}$, sample inlet: $1 \mu \mathrm{L}$, split-flow ratio: $20: 1$, carrier gas and flow velocity: $\mathrm{He}, 1.5 \mathrm{~mL} / \mathrm{min}$, oven temperature and duration: $200^{\circ} \mathrm{C}, 12 \mathrm{~min}$.

Phenol was extracted with $1 \%$ acetic acid solution from Cambridge filter pads and filters according to YC/T 2552008 procedure (21). Analysis was carried out by high pressure liquid chromatography (Agilent 1100, Agilent Technologies, Santa Clara, CA, USA) with scanning fluorescence detector on a Phenomenex Luna C18 (Phenomenex, Torrance, CA, USA) $(150 \times 4.6 \mathrm{~mm}, 5 \mu \mathrm{m})$ column, mobile phase A: $1 \%$ acetic acid solution, mobile phase B: acetic acid + methyl cyanide + water (1:30:69), column temperature: $30{ }^{\circ} \mathrm{C}$, column flow: $1 \mathrm{~mL} / \mathrm{min}$, sample inlet: $10 \mu \mathrm{L}$, elution gradient: $0 \mathrm{~min}$ : flow phase $\mathrm{A}$ $80 \%$, flow phase B $20 \% ; 15$ min: flow phase A $40 \%$, flow phase B $60 \%$; 23 min: flow phase A $0 \%$, flow phase B 100\%; 40 min: flow phase A $80 \%$, flow phase B 20\%; 5 min post run after $40 \mathrm{~min}$, flow phase A $80 \%$ and flow phase B 20\%. The fluorescence of phenol was measured initially at $284 \lambda \mathrm{ex}$ and $332 \lambda \mathrm{em}$. The conditions were changed after $8 \mathrm{~min}$ to $277 \lambda \mathrm{ex}$ and $319 \lambda \mathrm{em}$, after $20 \mathrm{~min}$ to $273 \lambda$ ex and $323 \lambda \mathrm{em}$, and after $40 \mathrm{~min}$ to $284 \lambda$ ex and $332 \lambda$ em.

$\mathrm{B}[a] \mathrm{P}$ was extracted with cyclohexane from Cambridge filter pads and filters according to GB/T 21130-2007 procedure (22). Analysis was carried out by GC-MS (Agilent 6890-5973, Agilent Technologies, Santa Clara, CA, USA on a DB-5MS glass capillary column with sample inlet and detector temperature set at $280^{\circ} \mathrm{C}$, sample inlet: $1 \mu \mathrm{L}$, carrier gas and flow velocity: $\mathrm{He}, 1.5 \mathrm{~mL} / \mathrm{min}$, programming temperature:

$150{ }^{\circ} \mathrm{C} \rightarrow\left(3{ }^{\circ} \mathrm{C} / \mathrm{min}\right) \rightarrow 250{ }^{\circ} \mathrm{C} \rightarrow\left(1{ }^{\circ} \mathrm{C} / \mathrm{min}\right) \rightarrow 275^{\circ} \mathrm{C}$. Detection was performed by mass spectrometry using the single ion monitoring (SIM) scan model.

$\mathrm{HCN}$ was extracted with $0.1 \mathrm{~mol} / \mathrm{L}$ sodium hydroxide solution from particulate phase, gas phase and filters according to YC/T 253-2008 procedure (23). Analysis was carried out using a continuous flow analyzer (Bran+Luebbe AA3, Seal Analytical Inc., Norderstedt, Germany). Cyanide ion reacts with chloramine $\mathrm{T}$, the reaction product cyanogen chloride then reacts with isonicotinic acid to generate pentene dialdehyde, finally a blue compound is generated by the reaction of pentene dialdehyde and 1,3dimethyl barbituric acid. Spectrophotometric analysis was carried out at $600 \mathrm{~nm}$.

Ammonia was extracted with $0.01 \mathrm{~mol} / \mathrm{L}$ hydrochloric acid from particulate phase, gas phase and filters according to YC/T 377-2010 procedure (24). Analysis was carried out by ion chromatography (Dionex ICS-3000, Thermo-Fisher Scientific Inc., Sunnyvale, CA, USA) using a Dionex ED50 column, suppressor current: $59 \mathrm{~mA}$, column tempera- 
ture: $30^{\circ} \mathrm{C}$, sample inlet: $25 \mu \mathrm{L}$, column flow: $1.2 \mathrm{~mL} / \mathrm{min}$, mobile phase A: water, mobile phase $\mathrm{B}: 0.1 \mathrm{~mol} / \mathrm{L}$ methane sulfonic acid, elution gradient: 0 min: flow phase A $88 \%$, flow phase B $12 \%$; 10 min: flow phase A $80 \%$, flow phase B $20 \%$; 20 min: flow phase A $88 \%$, flow phase B $12 \%$; 25 min: flow phase A $88 \%$, flow phase B $12 \%$. Detection was performed by an electrical conductivity detector (ECD, Dionex, Thermo-Fisher Scientific Inc., Sunnyvale, CA, USA. NNK was extracted with $0.01 \mathrm{~mol} / \mathrm{L}$ ammonium acetate from Cambridge filter pad and filters (25). Analysis was carried out by liquid chromatography-tandem mass spectrometry (Agilent 1200 - Applied Biosystems API 4000, AB Sciex, Framingham, MA, USA) using an Agilent poroshell 120 SB-C18 column, mobile phase A: $10 \mathrm{mmol} / \mathrm{L}$ ammonium acetate aqueous solution, mobile phase B: $0.5 \%$ formic acid-acetonitrile (volume ratio), sample inlet: 5.00 $\mu \mathrm{L}$, column flow: $0.4 \mathrm{~mL} / \mathrm{min}$, elution gradient: $0 \mathrm{~min}$ : flow phase A: $90 \%$, flow phase B: $10 \% ; 2$ min: flow phase A: $60 \%$, flow phase B: $40 \%$; 4 min: flow phase A: $40 \%$, flow phase B: $60 \%$; 6 min: flow phase A: $10 \%$, flow phase B: $90 \%, 10$ min: flow phase A: $90 \%$, flow phase B: $10 \%$. Detection was performed by tandem mass spectrometry using the multiple reaction monitoring (MRM) model.

Crotonaldehyde analysis was carried out by high pressure liquid chromatography using an Agilent 1200 HPLC, acclaim ${ }^{\circledR}$ explosive E2 column (Agilent Technologies, Santa Clara, CA, USA), sample inlet: $10.0 \mu \mathrm{L}$, column flow: $1.0 \mathrm{~mL} / \mathrm{min}$, mobile phase A: water, mobile phase B: acetonitrile, elution gradient: min: flow phase A: $50 \%$, flow phase B: $50 \%$; 25 min: flow phase A: $40 \%$, flow phase B: $60 \%$; 35 min: flow phase A: $20 \%$, flow phase B: $80 \%$; 40 min: flow phase A: $10 \%$, flow phase B: $90 \%$, 45 min: flow phase A: $50 \%$, flow phase B: $50 \%$. Detection was performed by a diode array detector (DAD) at $365 \mathrm{~nm}$.

\section{Filtration efficiencies of smoke components}

Cigarette samples were smoked under both ISO and HCI smoking regimes $(26,27)$. The components released in mainstream smoke and retained in the filter were determined respectively. The filtration efficiencies of filters (E) were calculated using the following formula:

$$
\mathrm{E}=\mathrm{W}_{1} /\left(\mathrm{W}_{1}+\mathrm{W}_{2}\right) \times 100 \%
$$

where $\mathrm{W}_{1}$ represents the amount of the component retained in the filter, and $\mathrm{W}_{2}$ represents the amount of the component present in mainstream smoke.

\section{Filter cutting, data calibration and retention distribution patterns}

After smoking, the filters were cut by an ILS-IIINM accurate laser cutting machine (Reson Technologies Inc., Taiwan, China). Figure 1 represents the schematic diagram of transverse and concentrical cutting of filters showing consecutive longitudinal and concentric segments respectively. For studies on the longitudinal retention distribution, filters were independently cut at different positions along the filter unit, and smoke components were determined in both cut filter segments. In the spatial retention distribution pattern study, filters were first cut transversely into three segments, and each segment was then cut concentrically at different radii $\left(r_{1}=1.26 \mathrm{~mm}, r_{2}=2.52 \mathrm{~mm}\right)$, respectively. Smoke components in the inner and outer segments were then determined.

Laser cutting may cause loss of filter retention smoke components due to high temperatures. The amount of smoke components lost either during transverse cutting or during concentric cutting is compensated in the two filter segments of the cut surface by calibration to adjust for $50 \%$ of the data loss. The calibrated smoke component concentrations in different filter segments were then processed by interpolation analysis and polynomial fitting, and filter retention distribution patterns of smoke components, including longitudinal distribution pattern and spatial distribution pattern, were obtained.

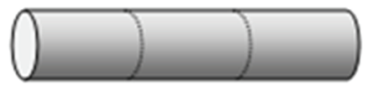

Transverse cut

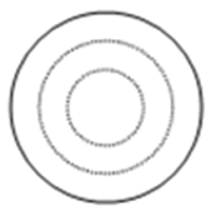

Concentric cut
Figure 1. Schematic illustrations of filter transverse cut and homocentric lengthways cut.

After smoking, smoke components in mainstream smoke, the whole filter and longitudinal and concentric segments of the filter were quantitatively analyzed respectively. The results for seven smoke components were presented as means of three replicates per sample, calculated as $\mathrm{mg} / \mathrm{cig}$ for nicotine, $\mu \mathrm{g} / \mathrm{cig}$ for phenol, $\mathrm{HCN}$, ammonia and crotonaldehyde and ng/cig for $\mathrm{NNK}$ and $\mathrm{B}[a] \mathrm{P}$. The relative standard deviations (RSD) were calculated from the three replicates. The RSD for seven components in mainstream smoke and filter retention varied at the ranges of $3 \%-8 \%$ and $4 \%-10 \%$, respectively. In comparison, the RSD for seven components in filter segments was relatively higher. The RSD for seven components in longitudinal segments (5-7 segments/filter) varied from 7\%-14\%, and the RSD for nicotine, phenol, $\mathrm{HCN}$, ammonia and crotonaldehyde in longitudinal and concentric segments ( 9 segments/filter) varied from $10 \%-21 \%$.

\section{RESULTS AND DISCUSSION}

\section{Filtration efficiency of smoke components under ISO and HCI smoking regimes}

The cigarette samples were smoked under ISO and HCI smoking regimes respectively. Nicotine, phenol, $\mathrm{B}[a] \mathrm{P}$, $\mathrm{NNK}$, crotonaldehyde, $\mathrm{HCN}$ and ammonia yields in mainstream smoke and amounts retained in filters were quantitatively analyzed. The yield of smoke components in mainstream smoke, the amount of component retained in the filter and the filtration efficiencies for of each smoke component under both ISO and HCI smoking regimes are presented in Table 2 . The filtration efficiencies of individual smoke components under the ISO smoking regime 
Table 2. Filtration efficiency of different smoke components under ISO and $\mathrm{HCl}$ smoking regimes.

\begin{tabular}{l|c|c|c|c|c|c|cc}
\hline $\begin{array}{l}\text { Smoking } \\
\text { regime }\end{array}$ & Content & $\begin{array}{c}\text { Nicotine } \\
(\mathrm{mg} / \mathrm{cig})\end{array}$ & $\begin{array}{c}\text { Phenol } \\
(\mu \mathrm{g} / \mathrm{cig})\end{array}$ & $\begin{array}{c}\mathrm{B}[\mathrm{a}] \mathrm{P} \\
(\mathrm{ng} / \mathrm{cig})\end{array}$ & $\begin{array}{c}\mathrm{HCN} \\
(\mu \mathrm{g} / \mathrm{cig})\end{array}$ & $\begin{array}{c}\text { Ammonia } \\
(\mu \mathrm{g} / \mathrm{cig})\end{array}$ & $\begin{array}{c}\text { NNK } \\
(\mathrm{ng} / \mathrm{cig})\end{array}$ & $\begin{array}{c}\text { Crotonaldehyde } \\
(\mu \mathrm{g} / \mathrm{cig})\end{array}$ \\
\hline \multirow{6}{*}{$\mathrm{ISO} \quad$} & Mainstream smoke & 1.17 & 7.71 & 9.72 & 93.8 & 8.59 & 4.19 & 21.2 \\
& Filter retention & 0.75 & 51.5 & 6.49 & 29.5 & 13.5 & 1.76 & 35.5 \\
& Total yield & 1.92 & 59.2 & 16.2 & 123.3 & 22.1 & 5.95 & 56.7 \\
& Filtration efficiency (\%) & 39.1 & 87.0 & 39.5 & 23.9 & 61.2 & 29.6 & 62.6 \\
$\mathrm{HCl}$ & Mainstream smoke & 2.34 & 9.85 & 16.7 & 208.9 & 18.6 & 10.2 & 50.4 \\
& Filter retention & 1.31 & 120.4 & 9.45 & 38.0 & 28.9 & 3.21 & 31.5 \\
& Total yield & 3.65 & 130.2 & 26.1 & 246.9 & 47.5 & 13.4 & 81.9 \\
& Filtration efficiency (\%) & 35.9 & 92.4 & 36.0 & 15.4 & 60.8 & 23.9 & 38.5 \\
\hline
\end{tabular}

ranged from $24 \%$ for $\mathrm{HCN}$ to $87 \%$ for phenol. Nicotine, phenol, $\mathrm{B}[a] \mathrm{P}$ and NNK are generally considered to be distributed in the particulate phase of mainstream smoke. The filtration efficiencies of nicotine and $\mathrm{B}[a] \mathrm{P}$ are about $39 \%$, which is considered to be close to particulate phase filtration efficiency. However, the filtration efficiency of phenol is $87 \%$, which is obviously higher than that of nicotine and $\mathrm{B}[a] \mathrm{P}$, indicating that the cellulose acetate filter shows obvious filtration selectivity for phenol. Compared with nicotine and $\mathrm{B}[a] \mathrm{P}\left(475^{\circ} \mathrm{C}\right)$, phenol has a lower boiling point $\left(182^{\circ} \mathrm{C}\right)$ and higher saturated vapor pressure which is favorable for filter retention. The filtration efficiency of NNK is lower than of nicotine and $\mathrm{B}[a] \mathrm{P}$, this may be due to its high boiling point $\left(424{ }^{\circ} \mathrm{C}\right)$, low saturated vapor pressure and strong polarity leading to relatively weak interaction between NNK and cellulose acetate fiber. $\mathrm{HCN}$, ammonia and crotonaldehyde are considered to be distributed in both the particulate phase and the gas phase. Ammonia and crotonaldehyde have relative high and similar filtration efficiencies, whereas $\mathrm{HCN}$ has the lowest filtration efficiency.

Compared with the ISO smoking regime, the total yields of all components increase substantially under HCI smoking regime. However, mainstream smoke yields and filter retention quantities show different trends. There is no obvious filtration efficiency variation for ammonia between the two smoking regimes. By contrast, nicotine, $\mathrm{B}[a] \mathrm{P}$, NNK, HCN and crotonaldehyde show a decreasing trend. In particular, the filter retention quantity of crotonaldehyde under HCI smoking regime is even lower than under ISO smoking regime. However, phenol has higher filtration efficiency under the HCI smoking regime, further explaining the strong interaction between phenol and acetate fiber. The filtration efficiency differences among smoke components illustrates the diversity of filtration and retention characteristics of different smoke components and indicates that cigarette smoke filtration is a very complex process.

\section{Retention patterns in consecutive filter segments for smoke components under ISO and HCI smoking regimes}

Figures 2 and 3 show the longitudinal retention concentration distribution patterns of smoke components under both ISO and HCI smoking regimes, respectively. The $\mathrm{X}$-axis represents the distance from the tobacco rod side to the smoking end of the filter. Under the ISO smoking regime, the distribution patterns of longitudinal retention concentra- tion for nicotine, phenol, $\mathrm{B}[a] \mathrm{P}, \mathrm{HCN}$, ammonia and NNK are generally similar. The retention concentration shows a decreased trend from the tobacco rod side to the smoking end at longitudinal direction. The concentration of the determined smoke components declines faster in the first half of the filter than in the second half, especially for phenol. Compared with other smoke components, crotonaldehyde shows a very particular distribution pattern. Its retention distribution shows an increasing trend in the first half of the filter and a decreasing trend in the second half, with a maximum concentration point in the middle. The longitudinal distribution patterns of these components under the HCI smoking regime are similar to those observed under the ISO smoking regime. Based on these results, it can be inferred that acetate fiber shows a high filtration selectivity to phenol, and the filtration and retention behavior of crotonaldehyde is significantly different from the other determined components.

Retention patterns in concentric filter segments for smoke components under ISO and HCI smoking regimes

Figures 4-8 show the spatial retention concentration distribution patterns of nicotine, phenol, $\mathrm{HCN}$, ammonia and crotonaldehyde respectively. In each graph, A is the retention concentration in different filter segments, and $\mathrm{B}$ is the corresponding spatial distribution pattern obtained from the data.

In the case of conventional cellulose acetate filter, there is no structure and filtration ability difference between the centre and the peripheral region of the filter. Smoke mainly flows through the central region of the filter. As shown in Figure 4, the retention distribution patterns of nicotine under ISO and HCI smoking regimes are very similar. Nicotine concentration shows a declining trend both from the filter central part to the periphery part in a radial direction and from the tobacco rod side to the smoking end in a longitudinal direction. The pattern for phenol in Figure 5 shows that its retention is mainly focused in the first third of the filter. This indicates that cellulose acetate fiber and/or glycerol triacetate have a stronger interaction with phenol than with nicotine, which is consistent with the longitudinal distribution and filtration efficiency results. The patterns for HCN and ammonia, as shown in Figures 6 and 7 , are different from nicotine and phenol. The retention concentration shows a declining trend from the tobacco rod side to the smoking end in a longitudinal direction, which is similar to nicotine and phenol. 

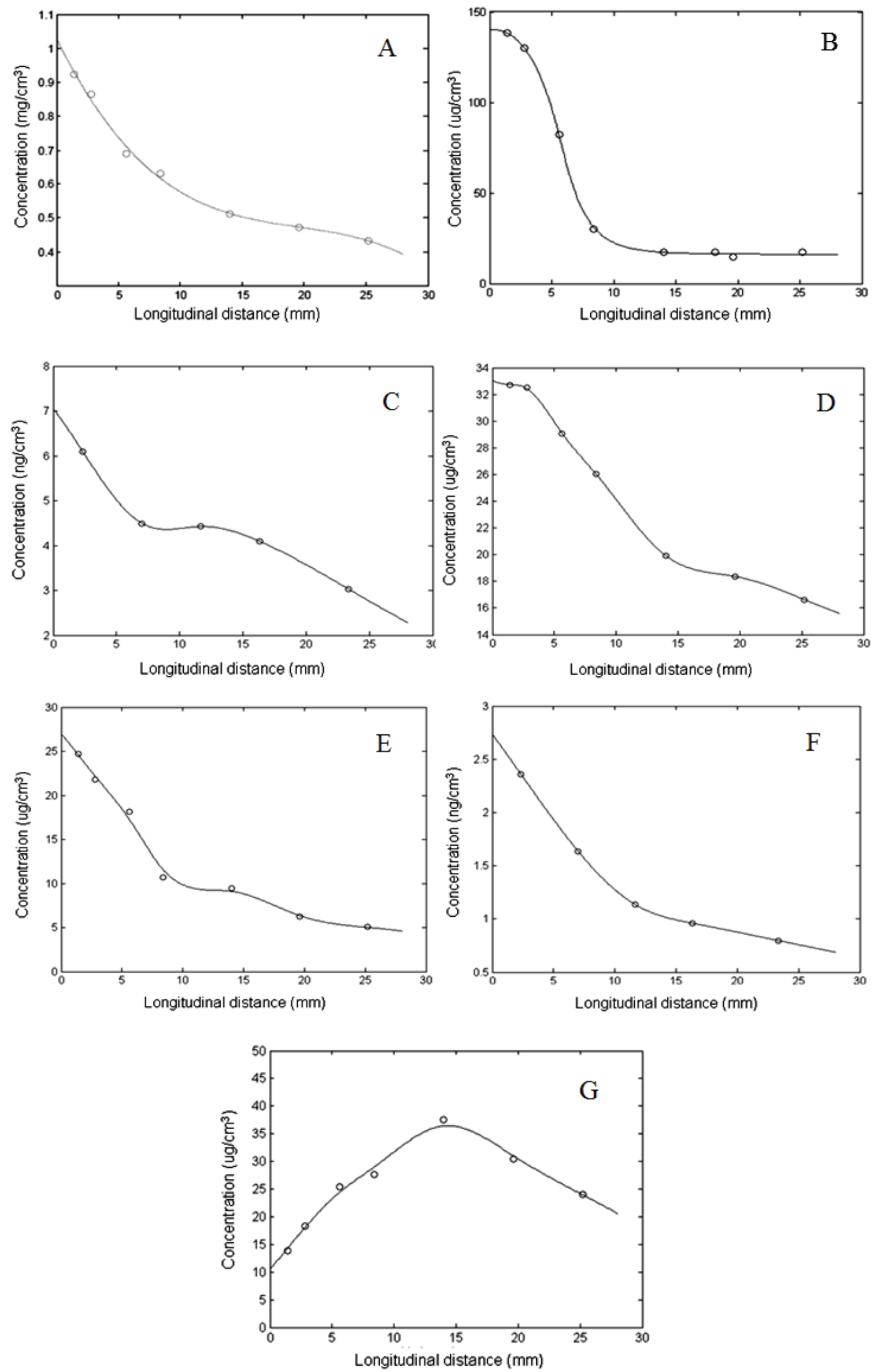

Figure 2. Longitudinal retention distribution patterns of (A) nicotine, (B) phenol, (C) B[a]P, (D) HCN, (E) ammonia, (F) NNK and (G) crotonaldehyde determined according to the ISO smoking regime. 

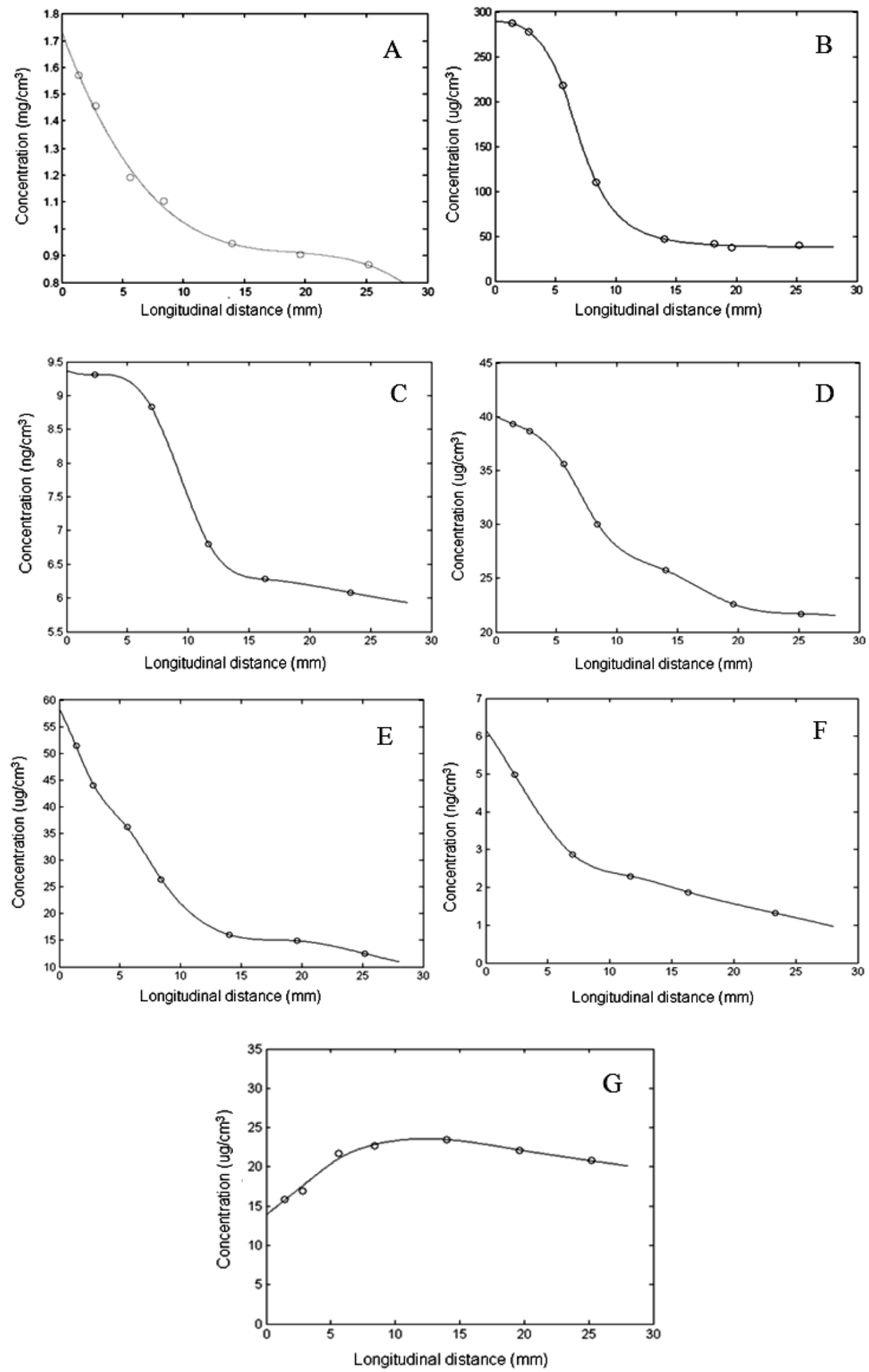

Figure 3. Longitudinal retention distribution patterns of (A) nicotine, (B) phenol, (C) B[a]P, (D) HCN, (E) ammonia, (F) NNK and (G) crotonaldehyde determined according to the $\mathrm{HCl}$ smoking regime. 
However, the retention concentration in the middle part is lower than the periphery part in a radial direction, especially for $\mathrm{HCN}$. This indicates that compared with nicotine and phenol, HCN and ammonia have different filtration and retention characteristics, which may be correlated with their boiling points. The boiling points of $\mathrm{HCN}\left(25.6{ }^{\circ} \mathrm{C}\right)$ and ammonia $\left(-33.5{ }^{\circ} \mathrm{C}\right.$, highly soluble in water) are much lower than nicotine $\left(247^{\circ} \mathrm{C}\right)$ and phenol $\left(182^{\circ} \mathrm{C}\right)$, and so smoke temperature should have greater influence on the retention of HCN and ammonia in the filter. Smoke temperature at the periphery part is lower than in the middle part in a radial direction, which is favorable for $\mathrm{HCN}$ and ammonia retention. Just like nicotine, the smoking regime change has no obvious influence on the patterns of phenol, HCN and ammonia. Figure 8 shows that crotonaldehyde has a very different distribution pattern. Under the ISO smoking regime, crotonaldehyde retention is mainly concentrated in the middle part and the smoking end of the filter in the longitudinal direction, which is completely different from other smoke components mentioned above. The most obvious crotonaldehyde retention concentration difference between the middle part and the peripheral part in a radial direction is at the tobacco side. The middle part is lower than the peripheral part, and approaches shifting to smoking end. Unlike other components, the crotonaldehyde distribution pattern under the HCI smoking regime was different from that observed under the ISO smoking regime. The retention concentration of the middle part is lower than in the peripheral part for the whole filter in a longitudinal direction. The retention concentration is also lower under HCI than under ISO smoking, indicating that less crotonaldehyde is retained in the filter under the HCI smoking regime, which is consistent with the filtration efficiency results. This special pattern is related to its physical and chemical properties. Crotonaldehyde has a low boiling point $\left(104^{\circ} \mathrm{C}\right)$ and is volatile. Furthermore, unlike $\mathrm{HCN}$ and ammonia, crotonaldehyde exists mainly in the undissociated form in cigarette smoke. It is hypothesized that the smoke flow during puffing causes desorption of crotonaldehyde retained in the filter, and that an adsorptiondesorption-adsorption of crotonaldehyde occurs in the filter during the smoking process. This desorption effect mainly happened during the last two puffs and at higher smoke temperatures, which is more obvious under the $\mathrm{HCI}$ smoking regime (16). Consequently, the distribution pattern of crotonaldehyde is significantly different from the other smoke components. Based on these results, the investigated smoke components have their own filtration and retention behavior, and the retention distribution pattern diversity of different components show the high degree of complexity of cigarette smoke filtration in the filters.

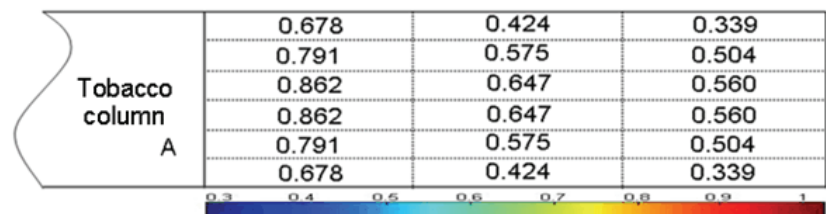

$\mathrm{B}$

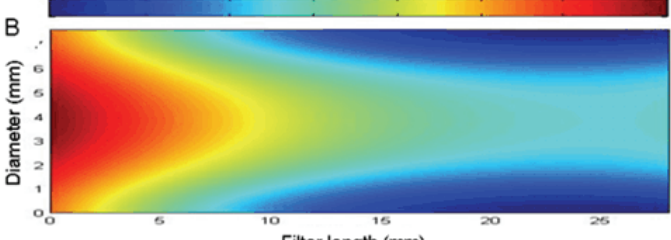

\begin{tabular}{|r|c|c|c|}
\hline \multirow{3}{*}{$\begin{array}{c}\text { Tobacco } \\
\text { column }\end{array}$} & 1.250 & 0.890 & 0.742 \\
\cline { 2 - 4 } & 1.475 & 0.986 & 0.971 \\
\cline { 2 - 4 } & 1.616 & 1.185 & 1.078 \\
\cline { 2 - 4 } & 1.616 & 1.185 & 1.078 \\
\hline & 1.475 & 0.986 & 0.971 \\
\hline
\end{tabular}

B

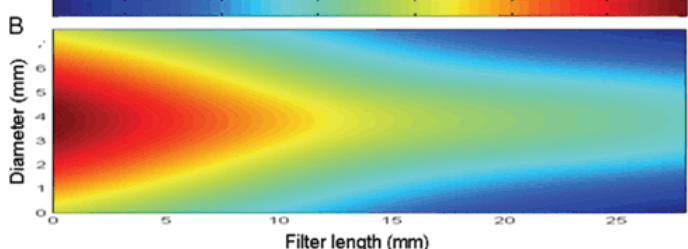

Figure 4. Retention spatial concentration distribution patterns of nicotine under ISO (left) and $\mathrm{HCl}$ (right) smoking regimes.

\begin{tabular}{|r|c|c|c|}
\hline & 88.40 & 22.80 & 13.07 \\
\cline { 2 - 4 } Tobacco & 97.79 & 25.64 & 14.24 \\
\cline { 2 - 4 } column & 136.49 & 34.12 & 17.16 \\
\cline { 2 - 4 } A & 136.49 & 34.12 & 17.16 \\
\cline { 2 - 4 } & 97.79 & 25.64 & 14.24 \\
\cline { 2 - 4 } & 88.40 & 22.80 & 13.07 \\
\hline
\end{tabular}

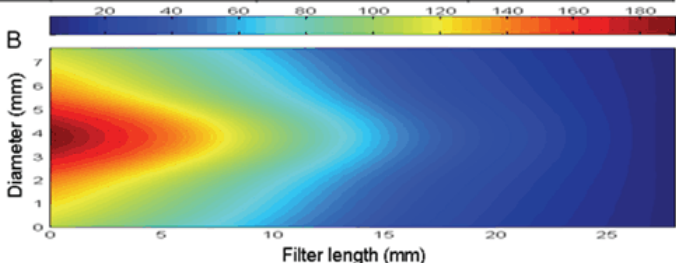

\begin{tabular}{|c|c|c|c|}
\hline \multirow{4}{*}{ Tobacco } & 185.76 & 64.72 & 24.65 \\
\cline { 2 - 4 } column & 193.42 & 69.84 & 29.22 \\
\cline { 2 - 4 } & 293.30 & 109.86 & 38.08 \\
\cline { 2 - 4 } A & 293.30 & 109.86 & 38.08 \\
\cline { 2 - 4 } & 193.42 & 69.84 & 29.22 \\
\cline { 2 - 4 } & 185.76 & 64.72 & 24.65 \\
\hline
\end{tabular}

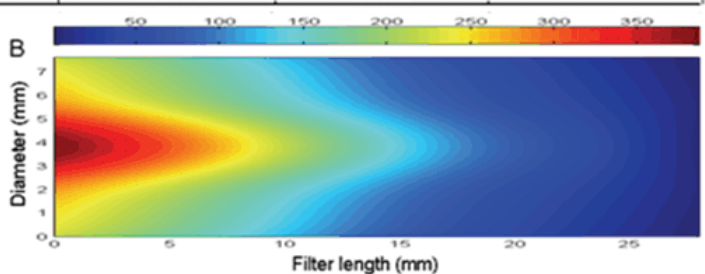

Figure 5. Retention spatial concentration distribution patterns of phenol under ISO (left) and $\mathrm{HCl}$ (right) smoking regimes. 


\begin{tabular}{|r|c|c|c|}
\hline \multirow{4}{*}{\begin{tabular}{c|c|c|} 
Tobacco \\
column
\end{tabular}} & 30.58 & 20.54 & 15.05 \\
\cline { 2 - 4 } & 24.58 & 18.89 & 15.72 \\
\cline { 2 - 4 }$A$ & 38.86 & 29.19 & 21.89 \\
\cline { 2 - 4 } & 38.86 & 29.19 & 21.89 \\
\cline { 2 - 4 } & 24.58 & 18.89 & 15.72 \\
\hline & 30.58 & 20.54 & 15.05 \\
\hline
\end{tabular}

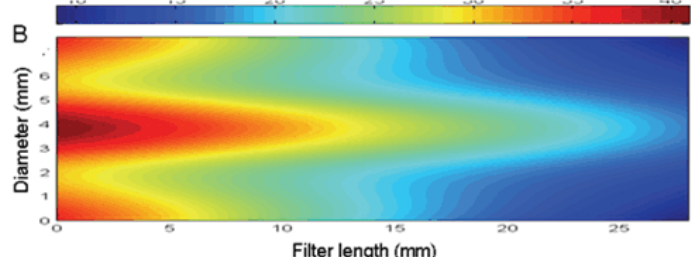

\begin{tabular}{|c|c|c|c|}
\hline \multirow{5}{*}{$\begin{array}{l}\text { Tobacco } \\
\text { column } \\
\text { A }\end{array}$} & 34.20 & 26.02 & 20.46 \\
\hline & 28.41 & 23.99 & 21.77 \\
\hline & 47.93 & 37.08 & 28.60 \\
\hline & 47.93 & 37.08 & 28.60 \\
\hline & 28.41 & 23.99 & 21.77 \\
\hline & 34.20 & 26.02 & 20.46 \\
\hline
\end{tabular}

$\mathrm{B}$

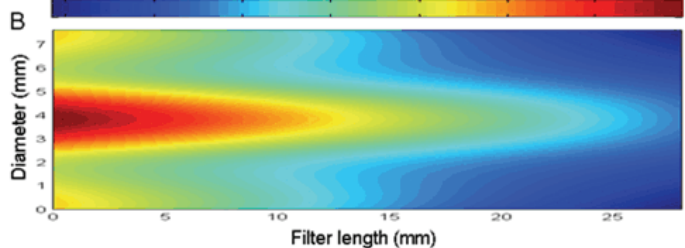

Figure 6. Retention spatial concentration distribution patterns of $\mathrm{HCN}$ under ISO (left) and $\mathrm{HCl}$ (right) smoking regimes.

\begin{tabular}{|r|c|c|c|}
\hline & 15.91 & 8.57 & 4.47 \\
\cline { 2 - 4 } Tobacco & 14.55 & 6.88 & 4.16 \\
\cline { 2 - 4 } column & 17.20 & 9.25 & 5.38 \\
\cline { 2 - 4 } A & 17.20 & 9.25 & 5.38 \\
\hline & 14.55 & 6.88 & 4.16 \\
\hline
\end{tabular}

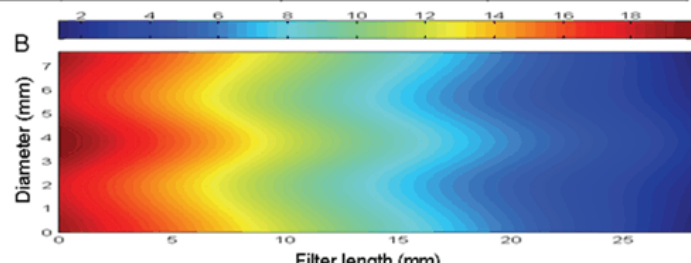

\begin{tabular}{|r|c|c|c|}
\hline & 36.86 & 14.09 & 8.82 \\
\cline { 2 - 4 } Tobacco & 35.95 & 12.97 & 7.52 \\
\cline { 2 - 4 } column & 45.92 & 16.77 & 9.46 \\
A & 45.92 & 16.77 & 9.46 \\
\cline { 2 - 4 } & 35.95 & 12.97 & 7.52 \\
\hline
\end{tabular}

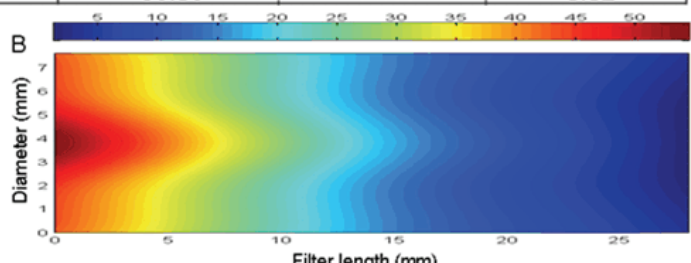

Figure 7. Retention spatial concentration distribution patterns of ammonia under ISO (left) and $\mathrm{HCl}$ (right) smoking regimes.

\begin{tabular}{|r|c|c|c|}
\hline & 20.85 & 30.64 & 31.81 \\
\cline { 2 - 4 } Tobacco & 15.64 & 29.71 & 32.59 \\
\cline { 2 - 4 } column & 33.53 & 45.89 & 38.96 \\
\cline { 2 - 4 } A & 33.53 & 45.89 & 38.96 \\
\cline { 2 - 4 } & 15.64 & 29.71 & 32.59 \\
\hline
\end{tabular}

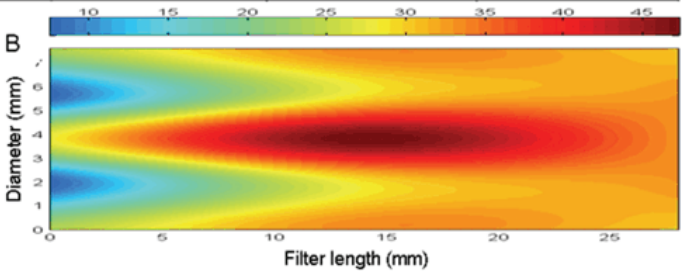

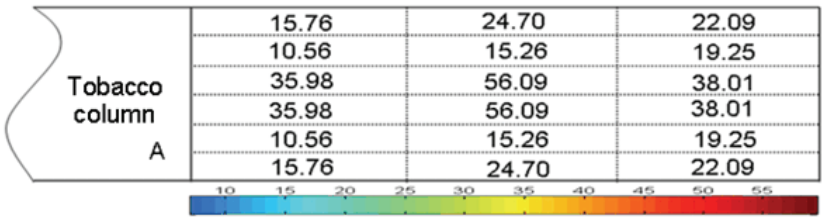

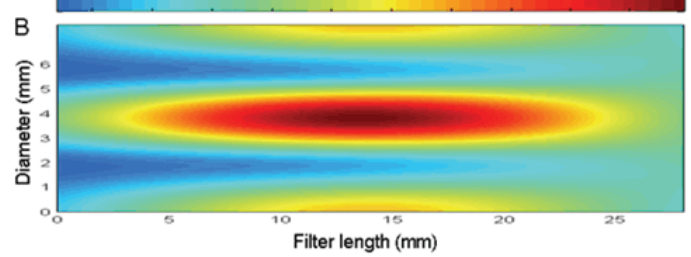

Figure 8. Retention spatial concentration distribution patterns of crotonaldehyde under ISO (left) and $\mathrm{HCl}$ (right) smoking regimes.

Based on the distribution patterns of these smoke components, the retention contribution rate of different filter parts to smoke components can be quantitatively evaluated. Table 3 shows the retention contribution rate of each of the three equal longitudinal segments of the filter (from the tobacco rod side to the smoking side) for nicotine, phenol, $\mathrm{B}[a] \mathrm{P}, \mathrm{HCN}$, ammonia, NNK and crotonaldehyde under both the ISO and HCI smoking regimes. The retention contribution rate of each part is stable for nicotine, $\mathrm{HCN}$ and $\mathrm{NNK}$, and varies at different levels for phenol, $\mathrm{B}[a] \mathrm{P}$, ammonia and crotonaldehyde under the two smoking regimes. For most smoke components, the first segment of the filter (at the tobacco rod side) has the highest retention contribution rate. The retention contribution rate of the first segment of the filter for phenol is even higher than $70 \%$, whereas that of the third segment of the filter is less than $10 \%$, indicating that the cellulose acetate filter shows significant filtration selectivity to phenol. 
Table 3. Filtration contribution rates of first, second and third filter parts to nicotine and other smoke components under ISO and $\mathrm{HCl}$ smoking regimes.

\begin{tabular}{|c|c|c|c|c|c|c|}
\hline \multirow{2}{*}{ Component } & \multicolumn{3}{|c|}{$\begin{array}{l}\text { Filtration contribution rate under } \\
\text { ISO smoking regime }\end{array}$} & \multicolumn{3}{|c|}{$\begin{array}{l}\text { Filtration contribution rate under } \\
\qquad \mathrm{HCl} \text { smoking regime }\end{array}$} \\
\hline & First (\%) & Second (\%) & Third (\%) & First (\%) & Second (\%) & Third (\%) \\
\hline Nicotine & 43.3 & 30.6 & 26.1 & 42.6 & 30.0 & 27.4 \\
\hline Phenol & 71.8 & 18.3 & 9.9 & 66.7 & 24.2 & 9.1 \\
\hline $\mathrm{B}[\mathrm{a}] \mathrm{P}$ & 41.6 & 34.6 & 23.8 & 41.8 & 30.2 & 28.0 \\
\hline $\mathrm{HCN}$ & 43.7 & 31.9 & 24.4 & 41.2 & 32.4 & 26.4 \\
\hline Ammonia & 55.2 & 28.6 & 15.2 & 63.0 & 23.3 & 13.7 \\
\hline NNK & 52.1 & 27.0 & 20.9 & 53.5 & 28.4 & 18.1 \\
\hline Crotonaldehyde & 25.0 & 38.0 & 37.0 & 26.2 & 40.4 & 33.4 \\
\hline
\end{tabular}

On the contrary, the first segment of the filter has the lowest retention contribution rate for crotonaldehyde under both smoking regimes, whereas the second segment of the filter has the highest retention contribution rate. Of course the filter can be divided into more segments and the retention contribution rate of each segment to different smoke components also can be quantitatively evaluated. It should be helpful both for filtration ability assessment of different filters and in filter design and improvement.

\section{CONCLUSION}

The filtration efficiencies of nicotine, phenol, $\mathrm{B}[a] \mathrm{P}, \mathrm{HCN}$, ammonia, NNK and crotonaldehyde in a cellulose acetate filter were evaluated under ISO and HCI machine-smoking regimes. Filters were cut to give consecutive and concentric segments and the smoke components retained in the divided filter segments were analyzed quantitatively, and the data processed with interpolation analysis and polynomial fitting. In this way, the retention distribution patterns of the selected smoke components were obtained. The relative contribution of different filter segments to retention of smoke components was quantitatively evaluated based on the retention distribution patterns. The filtration efficiencies of different components varied to a large extent. The filtration efficiencies of nicotine and most other components under HCI smoking regime are lower than under ISO smoking regime albeit to different extents, whereas phenol shows an opposite trend. Smoke components have their own filtration and retention behavior, and the retention distribution pattern diversity of different components show the high complexity of cigarette smoke filtration in the filter.

\section{REFERENCES}

1. Keith, C.H.: The Particulate Removal Efficiency of Cellulose Acetate Filters; 24 ${ }^{\text {th }}$ Tobacco Chemists' Research Conference, Montreal, Canada, October 1970.

2. Keith, C.H.: Physical Mechanisms of Smoke Filtration; Rec. Adv. Tob. Sci. 4 (1978) 25-45.

3. Hirota, K. and E. Takase: Filtration Efficiency of Cigarette Filters Made of Ultra Low Denier Acetate
Tow; CORESTA Congress, Kyoto, Japan, Smoke Science/Product Technology Groups, abstr. PT3, 2004, available at: http://www.coresta.org/Meetings/Past Abstracts/Kyoto2004-SmokeTech.pdf (accessed September 15, 2014).

4. Shibata, M., K. Hirota, E. Takase, and T. Matsumoto: Smoke Flow Analysis in Cigarette Filters; CORESTA Congress, Kyoto, Japan, Smoke Science/Product Technology Groups, abstr. PT1, 2004, available at: http://www.coresta.org/Meetings/Past_Abstracts/ Kyoto2004-SmokeTech.pdf (accessed September 15, 2014).

5. Keith, C.H. and J.C. Denick: Cigarette Filter Efficiency as Measured with a Homogeneous Solid Aerosol; Tob. Sci. 9 (1965) 116-120.

6. Overton, J.R.: Filtration of Cigarette Smoke: Relative Contributions of Inertial Impaction, Diffusional Deposition, and Direct Interception; Beitr. Tabakforsch. 7 (1973) 117-120.

7. Masafumi, T., K. Kazuhiko, and H. Takashi: Two Kinds of Filters Formaldehyde Filtering Behavior in Mainstream Smoke; 59 ${ }^{\text {th }}$ Tobacco Science Research Conference, Atlanta, GA, USA, September 2005.

8. Han, M., Y.H. Dai, and S.X. Tuo: Comparison of Filtration Effects of Cellulose Acetate and Modified Polypropylene Filters for Harmful Components in Cigarette Smoke; Chin. Tob. Sci. \& Tech. 272 (2010) 8-14.

9. Norman, V., A.M. Ihrig, R.A. Shoffner, and M.S. Ireland: The Effect of Tip Dilution on the Filtration Efficiency of Upstream and Downstream Segments of Cigarette Filters; Beitr. Tabakforsch. Int. 12 (1984) $178-185$.

10. Jing Y., C. Gong, K. Xian, C. Wang, and P. Lu: The Effects of Filter Ventilation on Flavor Constituents in Cigarette Smoke; Beitr. Tabakforsch. Int. 21 (2005) 280-285.

11. Kiefer, J.E.: Ventilation Filters and Their Effect on Smoke Composition; Rec. Adv. Tob. Sci. 4 (1978) 69-84.

12. Baker, R.R.: The Effect of Ventilation on Cigarette Combustion Mechanisms; Rec. Adv. Tob. Sci. 10 (1984) 88-150.

13. Formella K., T. Braumann, and H. Elmenhorst: The Influence of Different Parameters on the Semivolatile Composition of Mainstream Smoke; Beitr. Tabak- 
forsch. Int. 15 (1992) 123-128.

14. Dagnon, S., A. Stoilova, I. Ivanov, and S. Nikolova: The Effect of Cigarette Design on the Content of Phenols in Mainstream Tobacco Smoke; Beitr. Tabakforsch. Int. 24 (2011) 187-193.

15. Colard, S., T. Verron, R. Julien, X. Cahours, and S.W. Purkis: Relationship Between Cigarette Yields and Smoking Time Under Different Machine Smoking Regimes; Beitr. Tabakforsch. Int. 26 (2014) 4-18.

16. Purkis, S.W., C. Mueller, M. Intorp, and H. Seidel: The Influence of Cigarette Designs and Smoking Regimes on Vapour Phase Yields; Beitr. Tabakforsch. Int. 24 (2010) 33-46.

17. Yip, S.H., L.T. Taylor, M. Ashraf-Khorassani, J. Yu, M.F. Borgerding, W.M. Coleman III, and J.A. Bodnar: HPLC-MS Ddetermination of Acrolein and Acetone Generated from ${ }^{13} \mathrm{C}_{3}$-Labeled Glycerol Added to Cigarette Tobacco Using Two Machine-Smoking Regimes; Beitr. Tabakforsch. Int. 24 (2010) 48-57.

18. Kong, H.H., Y.Q. Pang, R. Zhou, G.L. Tang, and J.Z. $\mathrm{Wu}$ : Effects of Design Parameters of Cigarette Materials on Deliveries of Carbon Monoxide, Phenol and NNK in Mainstream Cigarette Smoke Under Intensive Smoking Regime; Chin. Tob. Sci. \&Tech. 309 (2013), 28-31.

19. China State Bureau of Quality and Technical Supervision (CSBQTS): GB/T 23355-2009. Cigarettes -- Determination of Nicotine in Smoke Condensates -Gas-Chromatographic Method (ISO 10315: 2000, MOD); CSBQZ, Bejing, 2009.

20. China State Bureau of Quality and Technical Supervision (CSBQTS): YC/T 154-2001. Cigarettes -Determination of Nicotine in Cigarette Filters -- GasChromatographic Method; CSBQZ, Bejing, 2001.

21. China State Bureau of Quality and Technical Supervision (CSBQTS): YC/T 255-2008. Cigarettes -Determination of Major Phenolic Compounds in Mainstream Cigarette Smoke -- High Performance Liquid Chromatographic Method; CSBQZ, Bejing, 2008.

22. China State Bureau of Quality and Technical Supervision (CSBQTS): GB/T 21130-2007. Cigarettes -- Determination of Benzo $[a]$ pyrene in Total Particulate Matter; CSBQZ, Bejing, 2007.
23. China State Bureau of Quality and Technical Supervision (CSBQTS): YC/T 253-2008. Cigarettes -Determination of Hydrogen Cyanide in Cigarette Mainstream Smoke -- Continuous Flow Method; CSBQZ, Bejing, 2008.

24. China State Bureau of Quality and Technical Supervision (CSBQTS): YC/T 377-2010. Cigarettes -Determination of Ammonia in Mainstream Cigarette Smoke -- Ion Chromatography Method; CSBQZ, Bejing, 2010.

25. Wu, M.J., Y.H. Dai, S.X. Tuo, N.N. Hu, Y. Li, and X.M. Chen: Analysis of Four Tobacco-Specific Nitrosamines in Mainstream Cigarette Smoke of Virginia Cigarettes by LC-MS/MS; J. Cent. South Univ. Technol. 15 (2008) 627-631.

26. International Organisation for Standardization (ISO): ISO 3308:2000. Routine Analytical Cigarette-Smoking Machine -- Definitions and Standard Conditions; ISO, Geneva, Switzerland.

27. World Health Organization (WHO): Decisions; Conference of the Parties to the WHO Framework Convention on Tobacco Control, Third Session, Durban, South Africa, November 17-22, 2008, WHO, Geneva, Switzerland, 2009, available at: http:// apps.who.int/gb/fctc/E/E_cop3.htm\#monter (accessed September 15, 2014).

Corresponding author:

Wen Jianhui

Technology Center of China Tobbaco Hunan Industrial Co. Ltd. Changsha 410007, China

E-mail:jhwen_hnu@aliyun.com 